\title{
Decreased occipital alpha oscillation in children who stutter during a visual Go/Nogo task
}

Johanna Piispala $\underline{a}^{\mathrm{b}} *$, Tuomo Starck $\underline{a}^{\mathrm{b}}$, Eira Jansson-Verkasalo ${ }^{\mathrm{e}}$, Mika Kallio $\underline{a}^{\mathbf{b}}$

a Department of Clinical Neurophysiology, Oulu University Hospital, Finland

${ }^{b}$ Medical Imaging, Physics and Technology-Research Group, University of Oulu, Finland

'Department of Psychology and Speech-Language Pathology, Speech-Language Pathology, University of Turku, Finland

*Corresponding author: Kajaanintie 50, 90029 OYS, Oulu, Finland. +358 407173850.

E-mail addresses: Johanna.Piispala@ppshp.fi (J. Piispala), Tuomo.Starck@oulu.fi (T. Starck), eira.janssonverkasalo@utu.fi (E. Jansson-Verkasalo), Mika.Kallio@oulu.fi (M. Kallio).

\section{Keywords}

Stuttering, children, EEG, alpha, theta, Go/Nogo

\section{Highlights}

* Children who stutter (CWS) exhibit less alpha activity than controls during a visual Go/Nogo task.

* Controls had clear occipital alpha between stimuli while CWS showed a shift to slower frequencies.

* CWS show atypical function of attentional gating possibly due to immaturity of the brain networks.

\footnotetext{
Abstract

Objective: Our goal was to discover attention- and inhibitory control- related differences in the main oscillations of the brain of children who stutter (CWS) compared to typically developed children (TDC).

Methods: We performed a time-frequency analysis using wavelets, fast Fourier transformation (FFT) and the Alpha/Theta power ratio of EEG data collected during a visual Go/Nogo task in 7-9 year old CWS and TDC, including also the time window between consecutive tasks.
} 
Results: CWS showed significantly reduced occipital alpha power and Alpha/Theta ratio in the "resting" or preparatory period between visual stimuli especially in the Nogo condition.

Conclusions: The CWS demonstrate reduced inhibition of the visual cortex and information processing in the absence of visual stimuli, which may be related to problems in attentional gating.

Significance: Occipital alpha oscillation is elementary in the control and inhibition of visual attention and the lack of occipital alpha modulation indicate fundamental differences in the regulation of visual information processing in CWS. Our findings support the view of stuttering as part of a wide-ranging brain dysfunction most likely involving also attentional and inhibitory networks.

\section{Introduction}

In developmental stuttering speech is dysfluent due to interruptions, repetitions and prolongations that complicate communication, often causing anxiety or fear of speaking. Many theories have associated stuttering severity with temperamental factors as high emotional reactivity (Conture et al., 2006; Bloodstein and Bernstein Ratner, 2008; Eggers and Van den Bergh, 2010) and self-regulation and inattention (Eggers et al., 2012; Eggers et al., 2013; Eggers and Jansson-Verkasalo, 2017; please see also review by Alm, 2014). Although the biological origin of stuttering is still uncertain, recent imaging studies have shown widespread structural and functional brain abnormalities in individuals who stutter when compared to fluently speaking controls (Belyk et al., 2015; Beal et al., 2007; Brown et al., 2005; Budde et al.; 2014; Chang et al.; 2009; Giraud et al., 2008; Jansson-Verkasalo et al., 2014; Neef et al., 2011; Preibisch et al., 2003; Salmelin et al., 2000; Sommer et al., 2002; Sowman et al., 2017; Watkins et al., 2008; for an overview, see reviews by Alm, 2004; Neef et al., 2015; Etchell et al., 2017). In addition or instead of implicating particular cortical areas, there is evidence of reduced connectivity in various white matter tracts such as tracts between auditory and motor areas, the corpus callosum or the frontal aslant tract (Cai, S. et al.; 2014; Civier et al., 2015; Kronfeld-Duenias et al., 2016). Similar, but not identical brain irregularities have been discovered in children who stutter (CWS) (Beal et al., 2013; Chang et al., 2008; Chang and Zhu, 2013; Chang et al., 2015; Misaghi et al., 2018). Chang et al. also recently described atypical functional brain network connections involving attentional and executive control related networks in CWS in a large fMRI study (Chang et al., 2017).

Considering the abovementioned findings, the CWS are likely to exhibit also attentional and inhibitory control problems. Posner and Petersen divided the attentional systems to subsystems (Posner and Petersen, 1990) that operate through several interacting functional brain networks (Visintin et al., 2015; Xuan et al., 2016; see review by Petersen and Posner, 2012). The vigilance network maintains alertness 
while the orienting network selects the crucial information produced by sensory systems. The executive control system, on the other hand, provides top-down control and deals e.g. with conflicting responses. A part of executive control, inhibitory control is a key factor in the regulation of impulsivity and enables attending to relevant stimuli only and thus accurate responses (Eggers and Jansson-Verkasalo, 2017; Rothbart, 1989; Rothbart and Posner, 1985).

We recently explored the inhibitory control of children who stutter by utilizing a visual Go/Nogo paradigm with simultaneous EEG and event-related potential measurement (Piispala et al., 2016; Piispala et al., 2017). In this task the Go-signal is to be reacted to while the Nogo-signal requires inhibition of response. In our studies the CWS showed significantly delayed Go-N2 component peak latency (Piispala et al., 2016) as well as atypically distributed and prolonged Nogo-N2 and diminished Nogo-P3 components when compared to typically developed children (TDC) (Piispala et al., 2017). These findings indicate problems in stimulus evaluating and classification and response selection as well as inhibitory control, despite similar accuracy and reaction times in the task.

However, ERPs can only give a narrow representation of the phase-locked neural activity in the task since ERPs usually contain parallel activity on multiple oscillatory frequencies, such as the alpha and theta band oscillations. With time-frequency analysis it is possible to gain a fuller insight into the spectral dynamics involved in the Go/Nogo task (Cavanagh and Frank, 2014; Cooper et al.; 2016; Harper et al., 2014; KirmiziAlsan et al., 2006). Alpha and theta are the major pre-stimulus oscillations that individually affect the main ERP amplitudes (De Blasio and Barry, 2013b; De Blasio and Barry, 2013a). High pre-stimulus alpha activity increases the P3 amplitudes in a Go/Nogo task independent of condition (De Blasio and Barry, 2013b). On the other hand, low pre-stimulus theta power produced higher Nogo-N2 and Go-P3, but reduced Nogo-P3, linking low pre-stimulus theta to improved cognitive processing (De Blasio and Barry, 2013a). Theta oscillation has been shown to specifically participate in the generation of the N2 component in Go/Nogo tasks (Cavanagh et al., 2012; Harper et al., 2014). In contrast, beta frequencies only influenced the early exogenous components (De Blasio and Barry, 2013b) and delta affected all components globally (De Blasio and Barry, 2013a).

Alpha-band oscillation between 8-12 Hz is the dominant rhythm in the brain (Berger, 1929; Klimesch, 1999; Klimesch, 2012). By many theories, alpha modulation operates as an attentional suppression and control mechanism operating via inhibition; high alpha activity or synchronization inhibits the processing of competing irrelevant information or distractors (Jensen and Mazaheri, 2010; Foxe and Snyder, 2011; Klimesch et al., 2007; see also reviews by Freunberger et al., 2011; Frey et al., 2015). Desynchronization of alpha oscillation is usually seen in the brain areas responsible for the processing of relevant, attended information (see reviews by Frey et al., 2015; Klimesch, 2012). Pre-stimulus alpha modulation targets 
attentional resources to the need-to-be-attended stimulus when cues are used. In those situations alpha is desynchronized over areas processing the attended stimuli and enhanced on other, task-irrelevant areas (Slagter et al., 2016; see reviews by Frey et al., 2015; Klimesch, 1999). In particular, high alpha amplitude or synchronization prior to a visual stimulus correlates negatively with visual perception and discrimination while desynchronization predicted good performance (Van Dijk et al., 2008; see also review by Hanslmayr et al., 2011).

Theta band is usually defined as oscillations within the $4-7 \mathrm{~Hz}$ frequency range and it has been connected to many cognitive functions, e.g. encoding new information, learning and working memory function (Chaieb et al., 2015; see reviews by Benchenane et al., 2011; Freunberger et al., 2011; Klimesch, 1999). In regard to inhibitory control, theta oscillation particularly in the frontal midline area may be crucial in cognitive control (Kirmizi-Alsan et al., 2006; Nigbur et al., 2011; for an overview, see review by Cavanagh and Frank, 2014).

Few studies have implemented EEG and time-frequency analysis in people with stuttering and mostly using speech paradigms (Sengupta et al. 2016; Sengupta et al., 2017; Salmelin et al., 2000; Mersov et al., 2016). In a resting state EEG study increased connectivity between motor speech and premotor areasat theta and alpha range oscillations was correlated to stuttering severity (Joos et al, 2014). Metzger et al. implemented a motor Go/Nogo task and discovered atypical network activation involving the basal ganglia in the preparation of the task in adults who stutter (Metzger et al., 2018).

These aforementioned studies used adult subjects, who may actually show major compensatory changes in response to years of dysfluency. Studies on children are thus highly valuable as they represent the early years of the clinical symptoms. Therefore, in this study on 7-9 year old children who stutter, we extended the evaluation of the EEG data collected previously and additional data during a visual Go/Nogo task (Piispala et al., 2016; Piispala et al.2017) from time domain ERP-analysis to time-frequency domain analysis in order to further differentiate the underlying parallel neuronal activations. We also expanded the exploration to a wider time frame including the pre-stimulus and late post-stimulus time windows to identify possible cue-related and preparatory as well as resting state differences. Considering the association between the N2 and P3 ERP-components and alpha and theta oscillations in inhibitory tasks, it is likely that the groups differ also by the magnitude, ratio and/or distribution of these oscillations. We focused on alpha and theta oscillations for their particular and relatively well-defined role in attention and cognitive control. So far there are no studies that we are aware of, on brain oscillations related to the Go/Nogo task in CWS. 


\section{Materials and methods}

\subsection{Participants}

Twelve children with stuttering (mean age 7.97 years, range 6.3-9.5 years; right-handed boys) and 12 typically developed, fluently speaking boys (mean age 8.01 years, range 5.8-9.6 years; one left-handed) participated in the study. The stuttering group consisted of 11 children already included in our previous studies (Piispala et al., 2016; 2017) and one new subject. In order to prevent sex-related confound only boys from the previous control group were now included. Stuttering was assessed using the Stuttering Severity Instrument SSI-3 and was graded very mild in 2, mild in 5 and moderate in 4 participants and severe in 1 participant. The groups did not differ significantly by age ( $p=.938$, t-test) or their performance in the Vocabulary ( $p=.163$, t-test) and Block Design ( $p=.636$, t-test) subtests of the Wechsler Intelligence Scale for Children, Third Edition (WISC-III, Wechsler, 1991). Prior to the study, all participants and their parent(s) received information about the study. A verbal approval was obtained from participants and the parent(s) gave an informed, written consent. The ethical committee of the Oulu University Hospital accepted the study in accordance with the declaration of Helsinki.

\subsection{Stimuli and procedure}

All children performed a visual Go/Nogo task, described in more detail earlier (Piispala et al., 2016). The task begins with a non-informative cue (a small white cross) for 500 ms, then either a Go (green, walking figure) or Nogo (red, standing figure) stimulus for 800 ms, followed by an empty, black screen for the remaining $1500 \mathrm{~ms}$ of a trial, resulting in a 2800 ms fixed inter-stimulus interval. One block contains $24 \mathrm{Go}$ and 24 Nogo stimuli in a pseudo-random order and each child performed 4-6 blocks, depending on the quality of the EEG. The child was instructed to press a mouse button for the Go stimulus and to refrain from pressing for Nogo stimulus. Correct Go responses (press within 250-3200 ms after a Go-stimulus) and Nogo responses (no press after a Nogo stimulus) were recorded.

\subsection{EEG recording and analysis}

During the task, EEG was continuously recorded with Brain Products software, a BrainAmp DC amplifier and an Acticap electrocap containing $64 \mathrm{Ag} / \mathrm{AgCl}$ electrodes. Sampling rate was $5000 \mathrm{~Hz}$ with $0.1 \mu \mathrm{V}$ resolution 
and a $0.016-1000 \mathrm{~Hz}$ on-line band pass was used. For eye movement recording, two electrodes were attached below and above the outer canthi of the left and right eye, respectively. Fcz was used as a common reference during the recording.

For the time-frequency analysis, the 4 most lateral channels were discarded due to the high likelihood of EMG-artifacts and the analysis was continued with 60 channels. The data was digitally filtered with a 0.1-25 $\mathrm{Hz}$ band pass filter to exclude EMG artifacts. After ocular correction all epochs containing higher than 250 $\mu \mathrm{V}$ voltages were excluded. The data was re-referenced to the linked mastoids and segmented from 700 pre-stimulus to 2100 ms post-stimulus, separately for correct Go and Nogo responses. After segmentation, the segments were inspected and any segment with excessive EMG or other artifacts was rejected from further analysis. The segments were averaged separately for each condition and at this point, the data were downsampled to $64 \mathrm{~Hz}$. For the determination of an appropriate baseline period, a combined TDC and CWS group mean wavelet graph was visually analyzed and the period between -600-(-500) ms was chosen as this period contained the least activity. Then a baseline corrected continuous wavelet transformation was performed for the averaged data of each child. The transformation was carried out with complex Morlet wavelet (Morlet parameter $=5$ ) using Gabor normalization. Frequency range of interest was limited to 3-20 $\mathrm{Hz}$ with $1 \mathrm{~Hz}$ steps resulting 18 frequency bins. The individual as well as the grand average wavelet graphs were inspected visually in both conditions (Fig 1.).

[Fig. 1. ]

\subsection{Statistical analysis}

The statistical analysis space of time-frequency wavelet data over channels defined by Acticap electrode layout was analyzed using the FieldTrip MATLAB toolbox (Oostenveld et al., 2011). The T-statistics of every channel-frequency-time - triplet is computed by non-parametric test for independent samples. Applied statistical approach is permutation resampling with 1000 permutations. The cluster permutation procedure was used to control for multiple comparisons over 192240 elements (60 channels x 18 frequency bins x 178 time points). Clusters are adjacent samples in this analysis space and are formed by thresholding the samples with $\mathrm{p}=0.05$ that yields 2.5 -percentile per tail for two-sided test. The cluster permutation procedure calculates cluster-level statistics by taking the sum of t-values over each cluster. Then the cluster-level significance level between CWS and TDC groups is calculated by permutation method where $p$ value is based on comparing the observed cluster statistics to the Monte-Carlo reference statistics. This $p$ value controls the false alarm rate and the threshold was set to $p=0.025$ for two-sided test.

For further examination of the differences seen in the wavelet graphs and the cluster analysis we carried out a fast Fourier transformation (FFT) in the Nogo condition. The time frame was narrowed to the 900- 
1800 ms time period, when the combined wavelet graph of both groups showed the most alpha activity. The visual stimulus has ended at $800 \mathrm{~ms}$ post-stimulus and during the selected time window the computer screen is empty, thus not requiring any visual processing. The first $100 \mathrm{~ms}$ and last $200 \mathrm{~ms}$ were left out to avoid technical artifacts and/or contamination from the stimulus processing. Both the grand average and individual FFT graphs were evaluated visually.

For a further statistical analysis an Alpha/Theta ratio was calculated from the mean power within the 7.5 12.5 $\mathrm{Hz}$ frequency range for alpha and $4-7.49 \mathrm{~Hz}$ for theta band in this time window. For comparison of the Alpha/Theta ratio between groups we used 12 frontal, central, parietal and occipital electrodes $(\mathrm{F} 3, \mathrm{Fz}, \mathrm{F} 4, \mathrm{C} 3, \mathrm{CZ}, \mathrm{C} 4, \mathrm{P3}, \mathrm{PZ}, \mathrm{P} 4, \mathrm{O} 1, \mathrm{Oz}, \mathrm{O} 2)$ and a linear mixed model analysis with the SPSS statistical analysis program ((IBM Corp. IBM SPSS Statistics for Windows, Version 23.0. Armonk, NY: IBM Corp). In the model Alpha/Theta ratio was used as dependent variable and Laterality (Left, Midline, Right) and AnteriorPosterior (Frontal, Central, Parietal and Occipital) as fixed effects and subject ID as a random effect. For the post hoc analysis of the significantly differing areas between and within groups two variables, Group (CWS/TDC) and Anterior-Posterior were combined into one variable. The Group-Anterior-Posterior variable was then used as a factor in the linear mixed model.

Due to the outliers seen in the individual FFT graphs, the Alpha/Theta ratio at Oz channel was compared between groups by Mann-Whitney U-test with and without these two outliers. However, since there is no valid methodological reason to leave these subjects out, their data is included in the final analysis using the linear mixed model.

\section{Results}

Statistical testing between groups showed CWS group to present significantly suppressed $(p=0.014)$ alpha activity across a broad time window starting from around $600 \mathrm{~ms}$ after the Nogo - stimuli (Fig. 2.). Decreased alpha activity cluster comprised mainly of parieto-occipital and frontal electrodes (for full electrode layout result please see supplementary material). In Go - condition the difference between the groups was not statistically significant.

[Fig. 2.]

The visual FFT analysis of the chosen "resting" period between 900 and 1800 ms post-stimulus revealed high alpha band activity in the posterior areas of the TDC group, but not in the CWS (Fig 3 a.) where the theta activity was more prominent. In the TDC the variability was wider with some individuals showing particularly enhanced alpha, whereas in the CWS all subjects showed very little alpha activity (Fig 3 b.).

[Fig. 3 a.] 
[Fig. 3 b.]

The boxplot of the Alpha/Theta ratio at $\mathrm{Oz}$ channel showed two distinct outliers as seen also in the individual FFT graphs (Fig 4.). However, when the Alpha/Theta ratio at $\mathrm{Oz}$ channel was compared both including ( $p=.001$, Mann-Whitney U-test) and excluding ( $p=.005$, Mann-Whitney U-test) these two subjects, the difference remains statistically significant, indicating that the difference between groups is not due to these outliers.

[Fig. 4.]

The mixed model analysis of the Alpha/Theta ratio supported the results of the visual analysis of the wavelet and FFT graphs. There was a highly significant Group x Anterior-Posterior main effect $(p<.000)$ with higher Alpha/Theta ratio in TDC than CWS. In pairwise comparisons between regions the Alpha/Theta ratio was significantly higher in the TDC than the CWS at the occipital leads ( $p<.000)$ (Fig. 5.).

[Fig. 5.]

\section{Discussion}

In our study the TDC showed distinct alpha band activity over the occipital areas from around $900 \mathrm{~ms}$ poststimulus when the visual stimulus had ended. However, in the CWS group this was significantly reduced and virtually no alpha was seen. Occipital alpha rhythm is an expected observation in eyes-closed restingstate EEG, but is also seen in eyes-open EEG although smaller in amplitude (Barry et al., 2007; Barry et al., 2009). When judged by visual analysis of our wavelet graphs as well as the previous ERP and topography analysis (Piispala et al., 2016; Piispala et al.,2017), the clear event-related activity fades off at around 600 ms. For that reason we assume that the EEG activity in the last post-stimulus time-window (900-2100 ms) resembles eyes-open resting-state EEG. However, in our study situation the child is most likely also concentrating on the upcoming task, in contrast to usual resting state studies. Therefore it may as well contain some active preparatory procedures instead of pure resting state activity.

In previous EEG-studies occipital alpha power increase has been associated with the inhibition of unnecessary or distracting visual information (van Dijk et al., 2008; Foxe and Snyder, 2011; Slagter et al., 2016) and with reduced cortical excitability (Romei et al., 2007). In simultaneous fMRI-EEG-studies alpha power has been linked to the blood oxygenation level dependent (BOLD) response to visual stimuli (Mayhew et al., 2013; Mo et al., 2013) supporting the role of alpha synchronization in the gating of attention. In our study the clear occipito-parietal alpha seen in the TDC during the black-screen stage likely represents efficient disengagement of visual perception and inhibition of the visual cortex. In contrast, it seems that in the CWS there is very little occipital alpha desynchronization and they maintain a highly 
receptive state and increased visual attention throughout the waiting period. The CWS may not be able to control and direct attentional resources proficiently to meaningful information only. From this point of view, low alpha power in the pre-stimulus period in CWS could indicate atypical attentional preparation to the upcoming task. One possible explanation is that the task induces more stress on the attentional abilities of the CWS and demands the use of more effort in e.g. visual orienting.

In the FFT-analysis the CWS showed significantly diminished Alpha/Theta ratio at the occipital area when compared to the TDC with CWS presenting higher theta power than alpha power. Developmental EEG studies have shown a spectral power shift to higher frequencies, decreasing theta/alpha ratio and increasing alpha peak frequency by age (Benninger et al., 1984; Clarke et al., 2001; Gasser et al., 1988; Miskovic et al, 2015). There are also developmental changes of the brain networks indexed by strengthening long-range alpha connectivity (Miskovic et al, 2015; Knyazev et al., 2017) and increasing EEG variability with age, proceeding from the posterior to anterior areas of the brain (Miskovic et al, 2016). Our findings of a shift towards slower oscillatory frequencies in the CWS could indicate more immature development of the brain and functional brain networks when compared to age-matched TDC.

Some brain regions show temporally connected activity in $\mathrm{fMRI}$ scans and/or coherent oscillation in EEG recordings during resting state and are considered to form a functional default mode network (DMN) which most likely reflects the ongoing intrinsic activity of the brain (Raichle et al; 2001; Laufs et al.; 2003, for an extensive review, see Raichle 2015). In contrast, task-related of task-positive networks such as the controlrelated frontoparietal network (FPN), the top-down attention regulating dorsal attentional network (DAN) and stimulus-driven ventral attention network (VAN) are activated during inhibitory and attentional tasks (Stevens et al., 2007; see also reviews by Corbetta et al, 2008; Parks and Madden, 2013; Vogel et al. 2010). The resting state and task-related network activities are anticorrelated; i.e. the DMN activation is seen with the concomitant inhibition of task-positive networks (Chai et al., 2012; Fox et al., 2005; Fox et al., 2009). The balance between these systems is crucial for executive control and attention and (Fox et al., 2005; Fox et. al, 2008; Raichle, 2015; reviews by Corbetta et al., 2008; Parks and Madden, 2013).

In the context of visual attention, high occipital alpha power in a resting state condition was positively correlated with DMN activity particularly in eyes-open condition in a simultaneous EEG-fMRI study (Mo et al., 2013). The authors suggested that DMN activation (and alpha activity) suppresses external visual input and thus enables intrinsic mental processing. In eyes-closed condition this is not needed and such activation was not seen. Furthermore, in the study by Mayhew et al, low pre-stimulus alpha-activity was concurrent with the inhibition of auditory networks as well as the DMN and led to enhanced positive BOLD responses to stimuli in the visual cortex (Mayhew et al., 2013). Knyazev et al have also coupled enhanced alpha-activity to the function on the DMN and possibly to internal mental processing (Knyazev et al., 2011). 
Thus the diminished alpha in the CWS in our study could reflect reduced activity of the DMN and less internal mental processing, perhaps due to imbalance between the DMN and attentional networks. This would corroborate the findings of Chang et al (Chang et al., 2017) and possibly present an electrophysiological indicator of abnormal brain network architecture in CWS compared to TDC. However, in some studies the parieto-occipital alpha power showed only weak or no correlation to the DMN (Bowman et al., 2017; Laufs et al. 2003; Neuner et al., 2014) but to the dorsal attentional network instead (Hacker et al., 2017). Then again, the DMN may act also in attentional tasks (Visintin et al., 2015; Popa et al, 2009). Therefore the exact relation of alpha activity, attention and the DMN activity remain indeterminate.

In regard to attention, children with ADHD or some subtypes of ADHD have frequently shown higher relative theta power along with reduced alpha and beta power when compared to controls (Clarke et al., 2011; Vollebregt et al., 2015; see review by Barry et al., 2003). Furthermore, children with ADHD exhibited absent posterior alpha modulation in response to cuing in a visuospatial task (Vollebregt et al., 2016) and in a cross-modality attentional task (Mazaheri et al, 2010). As the CWS in our study had parallel aberrations in the alpha and theta power ratio as children with ADHD, it could implicate similar abnormalities, perhaps in the brain network functions resulting in comparable attentional and cognitive control deficits. On the other hand, in the study by Chang et al. (2017) almost 15\% of the subjects with stuttering were diagnosed with ADHD later during follow-up and more than $10 \%$ were given some other developmental or psychiatric diagnosis. Our findings lend cautious support to the hypothesis that developmental stuttering and ADHD involve some related malfunction of attentional control.

\section{Caveats and confounds}

One consideration is the effect of the processing of the task stimuli. As in Nogo condition, clear alpha activity was indeed evident in the TDC in the same time window in the Go condition, too. However, the difference to the CWS did not reach statistical significance. The motor response in the Go condition may affect the oscillatory activity even in this later time window obscuring the differences in the statistical analysis.

On the other hand, we cannot rule out the use of some compensating attentional mechanisms in CWS, as the behavioural performance was equal between groups (Piispala et al., 2016). In a recent visual spatial attention study comparing elderly and young subjects, the older subjects showed reduced occipital alpha power during the task but also in the resting or baseline state (Van der Waal et al., 2017), similarly to the CWS in our task. The elderly did not show a typical lateralization of alpha in this spatial task, either, as the younger subjects did. Instead the older participants had excessive high-frequency lateralization possibly 
indicating the use of some other resources to complete the task. Also another study reported diminished parieto-occipital alpha modulation by cue in the elderly when compared to young, but activation of centrally located beta frequency activity as possible alternative coping mechanism (Deiber et al., 2013). In our study, however, we did not analyze the higher frequencies in order to reduce artifact due to muscle activity, as it may overlap especially the gamma, but also beta frequency brain activity. Typical of child data, some children in our study still showed excessive muscle activity despite all efforts to record clean EEG.

The sample size in our study is small despite continuous recruiting due to the strict exclusion criteria. We only accepted children with pure stuttering and no other neurological or developmental issues to avoid confound. As commonly known and also seen in the study of Chang et al. (2017), stuttering is frequently associated with concomitant neurological and neuropsychological problems and many candidates for our study were rejected for this reason. However, the differences were clear even in this small group and in children with no other diagnosis besides stuttering.

\section{Conclusion}

Our findings of significant differences in the key components of the brain's oscillatory activity in a nonspeech related setting further stress the fact that stuttering is more than a speech related disorder. Our results express the electrophysiological correlates of the extensive brain deviations found in earlier imaging studies and support the role of EEG analysis as a useful and sensitive tool in discovering these group-level differences.

\section{Acknowledgements}

We are grateful to all the children and the families who participated in this study. We also thank M.Sc. Risto Bloigu from Medical Informatics and Statistics Research Group, the University of Oulu, technician Raija Remes, systems specialist Hannu Wäänänen and M. Sc. Kalervo Suominen from the Department of Clinical Neurophysiology, Oulu University Hospital, for their help in performing and reporting of this study.

\section{Financial disclosure}

This study was supported by the Academy of Finland (grant 128840) and general research funding from the Finnish Government, granted by Oulu University Hospital. The funding sources did not have any role in the design of the study, collection of data or the analysis, interpretation or reporting of the data. 
None of the authors have potential conflicts of interest to be disclosed.

\section{References}

Alm, P.A. (2004). Stuttering and the basal ganglia circuits: A critical view of possible relations. J Commun Disord, 37, 325-369.

Alm, P.A. (2014). Stuttering in relation to anxiety, temperament, and personality: Review and analysis with focus on causality. J Fluency Disord, 40, 5-21.

Barry, R.J., Clarke, A.R. and Johnstone, S.J. (2003). A review of electrophysiology in attentiondeficit/hyperactivity disorder: I. Qualitative and quantitative electroencephalography. Clin Neurophys, 114, 171-183.

Barry, R.J., Clarke, A.R., Johnstone, S.J., Magee, C.A. and Rushby, J.A. (2007). EEG differences between eyesclosed and eyes-open resting conditions. Clin Neurophys, 118, 2765-2773.

Barry, R.J., Clarke, A.R., Johnstone, S.J. and Brown, C.R. (2009). EEG differences in children between eyesclosed and eyes-open resting conditions. Clin Neurophys, 120,1806-1811.

Beal, D.S., Gracco, V.L., Brettschneider, J., Kroll, R.M. and De Nil, L.F. (2013). A voxel-based morphometry (VBM) analysis of regional grey and white matter volume abnormalities within the speech production network of children who stutter. Cortex, 49, 2151-2161.

Beal, D.S., Gracco, V.L., Lafaille, S.J., and de Nil, L.F. (2007). Voxel-based morphometry of auditory and speech-related cortex in stutterers. Neuroreport, 18(12), 1257-1260.

Belyk, M, Kraft, S.J. and Brown, S. (2015). Stuttering as a trait or state - an ALE meta-analysis of neuroimaging studies. Eur J Neurosci, 41, 275-284

Benchenane, K., Tiesinga, P.H. and Battaglia, F.P. (2011). Oscillations in the prefrontal cortex: a gateway to memory and attention. Curr Opin Neurobiol, 21, 475-485.

Benninger, C., Matthis, P., Scheffner, D. (1984). EEG development of healthy boys and girls. Results of a longitudinal study. Electroencephalogr Clin Neurophysiol, 57, 1-12. 
Berger, H. (1929). Über das Elektroenkephalogramm des Menschen. 1st report. Arch Psychiat Nervenkr, 87, 527-570

Bloodstein, O., and Bernstein Ratner, N, (2008). A Handbook of Stuttering. Clifton Park: Thompson.

Bowman, A.D., Griffis, J.C., Visscher, K.M., Dobbins, A.C., Gawne, T.J., DiFrancesco, M.W. and Szaflarski, J.P.(2017). Relationship between alpha rhythm and the default mode network: An EEG-fMRI study. J Clin Neurophysiol, 34, 527-533.

Brown, S., Ingham, R.J., Ingham, J.C., Laird, A.R. and Fox, P.T. (2005). Stuttered and fluent speech production: An ALE meta-analysis of functional neuroimaging studies. Hum Brain Mapp, 25, 105-117.

Budde, K.S., Barron, D.S. and Fox, P.T. (2014). Stuttering, induced fluency, and natural fluency: A hierarchical series of activation likelihood estimation meta-analyses. Brain Lang, 139, 99-107.

Cai, S., Tourville, J.A., Beal, D.S., Perkell, J.S., Guenther, F.H. and Ghosh, S.S. (2014). Diffusion imaging of cerebral white matter in persons who stutter: evidence for network-level anomalies. Front Hum Neurosci, $11 ; 8: 54$

Cavanagh, J.F., Zambrano-Vazquez, L. and Allen, J.J.B. (2012). Theta lingua franca: A common mid-frontal substrate for action monitoring processes. Pshychophysiology, 49, 220-238.

Cavanagh, J.F. and Frank, M.J. (2014). Frontal theta as a mechanism for cognitive control. Trends Cogn Sci, $18,414-421$.

Chai, X.J., Castañón, A.N., Öngür, D. and Whitfield-Gabrieli, S. (2012). Anticorrelations in resting state networks without global signal regression. Neurolmage, 59, 1420-1428.

Chaieb, L., Leszczynski, M, Axmacher, N., Höhne, M., Elger, C.E. and Fell, J. (2015). Theta-gamma phasephase coupling during working memory maintenance in the human hippocampus. Cogn Neurosci, 6, 149157.

Chang, S-E., Angstadt, M., Chow, H.M., Etchell, A.C., Garnett, E.O., Choo, A.L, Kessler, D., Welsh, R.C. and Sripada, C. (2017). Anomalous network architecture of the resting brain in children who stutter. J Fluency Disord, doi: 10.1016/j.jfludis.2017.01.002.

Chang, S.E., Erickson, K.E., Ambrose, N.G., Hasegawa-Johnson, M.A. and Ludlow, C.L. (2008). Brain anatomy differences in childhood stuttering. Neuroimage, 39, 1333-1344.

Chang, S-E., Kenney, M.K., Loucks, T.M.J. and Ludlow, C.L. (2009). Brain activation abnormalities during speech and non-speech in stuttering speakers. Neuroimage, 46, 201-212. 
Chang, S-E. and Zhu, D.C. (2013). Neural network connectivity differences in children who stutter. Brain $136,3709-3726$.

Chang, S-E., Zhu, D.C., Choo, A.L. and Angstadt, M. (2015). White matter neuroanatomical differences in young children who stutter. Brain, 138, 694-711

Civier, O., Kronfeld-Duenias, V., Amir, O., Ezrati-Vinacour, R.andBen-Shachar, M. (2015). Reduced franctional anisotropy in the anterior corpus callosum is associated with reduced speech fluency in persistent developmental stuttering. Brain Lan., 143, 20-31.

Clarke, A.R., Barry, R.J., Dupuy, F.E., Heckel, L.D., McCarthy, R., Selikowitz, M. and Johnstone, S.J. (2011). Behavioural differences between EEG-defined subgroups of children with attention-deficit/hyperactivity disorder. Clin Neurophys, 122, 1333-1341.

Clarke, A.R., Barry, R.J., McCarthy, R. and Selikowitz, M. (2001). Age and sex effects in the EEG: development of the normal child. Clin Neurophys, 112, 806-814.

Conture, E., Walden, T., Graham, C., Arnold, H., Hartfield, H., Karrass, J., et al. (2006). Communicationemotional model of stuttering. In N. Bernstein Ratner and J. Tetnowski (eds), Stuttering research and practice: Contemporary issues and approaches (pp. 17-46). Mahwah, NJ: Lawrence Erlbaum Associates.

Cooper, P.S., Darriba, A., Karayanidis, F., and Barceló, F. (2016). Contextually sensitive power changes across multiple frequency bands underpin cognitive control. Neurolmage, 132, 499-511.

Corbetta, M., Patel, G. and Shulman, G.L. (2008). The reorienting system of the human brain: From environment to theory of mind. Neuron, 58, 306-324.

De Blasio, F.M. and Barry, R.J. (2013a). Prestimulus delta and theta determinants of ERP responses in the Go/NoGo task. Int J Psychophysiol, 87, 279-288.

De Blasio, F.M. and Barry, R.J. (2013b). Prestimulus alpha and beta determinants of ERP responses in the Go/NoGo task. Int J Psychophysiol, 89, 9-17.

Deiber, M-P, Ibanez, V., Missonnier, P., Rodriguez, C. and Giannakopoulos, P. (2013). Age-associated modulations of cerebral oscillatory patterns related to attention control. Neurolmage, 82, 531-546.

Eggers, K., De Nil, L,, and Van den Bergh, B.R.H. (2010). Temperament dimensions in stuttering and typically developing children. J Fluency Disord, 35, 355-372.

Eggers, K., De Nil, L., and Van den Bergh, B.R.H. (2012). The efficiency of attentional networks in children who stutter. J Speech Lang Hear Res, 55, 946-959. 
Eggers, K., De Nil, L. and Van den Bergh, B.R.H. (2013). Inhibitory control in childhood stuttering. J Fluency Disord, 38, 1-13.

Eggers, K. and Jansson-Verkasalo, E. (2017). Auditory attentional set-shifting and inhibition in children who stutter. J Speech Lang Hear Res, 60, 3159-3170.

Etchell, A.C., Civier, O., Ballard, K.J. and Sowman, P.F. (2017). A systematic literature review of neuroimaging research on developmental stuttering between 1995 and 2016. J Fluency Disord, doi: 10.1016/j.jfludis.2017.03.007.

Fox, M.D., Snyder, A.Z., Vincent, J.L., Corbetta, M., Van Essen, D.C. and Raichle, M.E. (2005). The human brain is intrinsically organized into dynamic, anticorrelated functional networks. Proc Natl Acad Sci, 102, 9673-9678.

Fox, M.D., Zhang, D., Snyder, A.Z. and Raichle, M.E. (2009). The global signal and observed anticorrelated resting state brain networks. J Neurophysiol, 101, 3270-3283.

Foxe, J.J. and Snyder, A.C. (2011). The role of alpha-band oscillations as a sensory suppression mechanism during selective attention. Front Psychol, 2, 154

Freunberger, R., Werkle-Bergner, M., Griesmayr, B., Lindenberger, U. and Klimesch, W. (2011). Brain oscillatory correlates of working memory constraints. Brain Res, 1375, 93-102.

Frey, J.N., Ruhnau, P. and Wisz, N. (2015). Not so different after all: The same oscillatory processes support different types of attention. Brain Res, 1626, 183-197

Gasser, T., Verleger, R., Bächer, P., Sroka, L. (1988). Development of the EEG of school-age children and adolescents. I. Analysis of band power. Electroencephalogr Clin Neurophysiol, 69, 91-99.

Giraud, A-L., Neumann, K., Bachold-Levi, A-C., von Gudenberg, A.W., Euler, H.A., Lanfermann, H., and Preibisch, C. (2008). Severity of dysfluency correlates with basal ganglia activity in persistent developmental stuttering. Brain Lang, 104, 190-199.

Hacker, C.D., Snyder, A.Z., Pahwa, M., Corbetta, M. and Leuthardt, E.C. (2017). Frequency-specific electrophysiologic correlates of resting state fMRI networks. Neurolmage, 149, 446-457.

HansImayr, S., Gross, J., Klimesch, W. and Shapiro, K.L. (2011). The role of alpha oscillations in temporal attention. Brain Res Rev, 67, 331-343.

Harper, J., Malone, S.M. and Bernat, E.M. (2014). Theta and delta band activity explain N2 and P3 ERP component activity in a go/no-go task. Clin Neurophysiol, 125, 124-132. 
Jansson-Verkasalo, E., Eggers, K., Järvenpää, A., Suominen, K., Van den Bergh, B., De Nil, L., and Kujala, T. (2014). Atypical central auditory speech-sound discrimination in children who stutter as indexed by the mismatch negativity. J Fluency Disord, 41, 1-11.

Jensen, O. and Mazaheri, A. (2010). Shaping functional architecture by oscillatory alpha activity: gating by inhibition. Front Hum Neurosci, 4, http://dx.doi.org/10.3389/fnhum.2010.00186

Joos, K., De Ridder, D., Boey, R.A. and Vanneste, S. (2014). Functional connectivity changes in adults with developmental stuttering: a preliminary study using quantitative electro-encephalography. Front Hum Neurosci, 8, 783, doi: 10.3389/fnhum.2014.00783.

Kirmizi-Alsan, E., Bayraktaroglu, Z., Gurvit, H., Keskin, Y.H., Emre, M. and Demiralp, T. (2006). Comparative analysis of event-related potentials during Go/NoGo and CPT: Decomposition of electrophysiological markers of response inhibition and sustained attention. Brain Res., 1104, 114-128.

Klimesch, W. (1999). EEG alpha and theta oscillations reflect cognitive and memory performance: a review and analysis. Brain Res Rev, 29, 169-195.

Klimesch, W. (2012). Alpha-band oscillations, attention and controlled access to stored information. Trends Cogn Sci, 16, 606-617.

Klimesch, W., Sauseng, P. and HansImayr, S. (2007). EEG alpha oscillations: The inhibition-timing hypothesis. Brain Res Rev., 53, 63-88

Knyazev, G.G., Slobodskoj-Plusnin, J.Y., Bocharov, A.V. and Pylkova, L.V. (2011). The default mode network and EEG alpha oscillations: An independent component analysis. Brain Res, 1402, 67-79.

Knyazev, G.G., Savostyanov, A.N., Bocharov, A.V., Slobodskaya, H.R., Bairova, N.B., Tamozhnikov, S.S., and Stepanova, V.V. (2017). Effortful control and resting state networks: A longitudinal EEG study. Neuroscience, 346, 365-381.

Kronfeld-Duenias, V., Amir, O., Ezrati-Vinacour, R., Civier, O. and Ben-Scachar, M. (2016). Dorsal and ventral language pathways in persistent developmental stuttering. Cortex, 81, 79-92.

Laufs, H., Krakow, K., Sterzer, P., Eger, E., Beyerle, A., Salek-Haddadi, A. and Kleinschmidt, A. (2003) Electroencephalic signatures of attentional and cognitive default modes in spontaneous brain activity fluctuations at rest. Proc Natl Acad Sci. 100, 19, 11053-11058. 
Mayhew, S.D., Ostwald, D., Porcaro, C. and Bagshaw, A.P. (2013). Spontaneous EEG alpha oscillation interacts with positive and negative BOLD responses in the visual-auditory cortices and default-mode network. Neurolmage, 76, 362-372.

Mazaheri, A., Coffey-Corina, S., Mangun, G.R., Bekker, E.M., Berry, A.S. and Corbett, B.A. (2010). Functional disconnection of frontal cortex and visual cortex in attention-deficit/hyperactivity disorder. Biol Pshychiatry, 67, 617-623.

Mersov, A-M., Jobst, C., Cheyne, D.O. and De Nil, L. (2016). Sensorimotor oscillations prior to speech onset reflect altered motor networks in adults who stutter. Front Hum Neurosci., 10, 443, doi: 10.3389/fnhum.2016.00443

Metzger, F.L., Auer, T., Helms, G., Paulus, W., Frahm, J., Sommer, M. and Neef, N.E. (2018). Shifted dynamic interactions between subcortical nuclei and inferior frontal gyri during response preparation in persistent developmental stuttering. Brain Struct Funct, 223, 165-182.

Misaghi, E., Zhang, Z., Gracco, V.L., De Nil, L.F. and Beal, D.S. (2018). White matter tractography of the neural network for speech-motor control in children who stutter. Neurosci Lett, 668, 37-42.

Miskovic, V. Ma, X., Chou, C-A., Fan, M., Owens, M., Sayama, H. and Gibb, B.E. (2015). Developmental changes in spontaneous electrocortical activity and network organization from early to late childhood. Neurolmage, 118, 237-247.

Miskovic, V., Owens, M., Kuntzelman, K. and Gibb, B.E. (2016). Charting moment-to-moment brain signal variability from early to late childhood. Cortex, 83, 51-61.

Mo, J., Liu, Y., Huang, H. and Ding, M. (2013). Coupling between visual alpha oscillations and default mode activity. Neurolmage, 68, 112-118.

Neef, N.E., Anwander,A., and Friederici, A.D. (2015) The neurobiological grounding of persistent stuttering: from strucute to function. Curr Neurol Neurosci Rep., 15:63.

Neef, N.E., Jung, K., Rothkegel, H., Pollok, B., Wolff von Gudenberg, A., Paulus, W. and Sommer, M. (2011). Right-shift for non-speech motor processing in adults who stutter. Cortex, 47, 945-954.

Neuner, I., Arrubla, J., Werner, C.J., Hitz, K., Boers, F., Kawohl, W. andand Shah, N.J. (2014). The default mode network and EEG regional spectral power: A simultaneous fMRI-EEG study. PLoS ONE 9(2); e88214, doi:10.1371/journal.pone.0088214 
Nigbur, R., Ivanova, G. and Stürmer, B. (2011). Theta power as a marker for cognitive interference. Clin Neurophysiol, 122, 2185-2194

Oostenveld, R., Fries, P., Maris, E. and Schoeffelen, J.M. (2011) FieldTrip: Open source software for advanced analysis of MEG, EEG, and invasive electrophysiological data. Comput Intell Neurosci. 2011:156869. doi: 10.1155/2011/156869

Parks, E.L. and Madden, D.J. (2013). Brain connectivity and visual attention. Brain Connect, 3, 317-338.

Petersen, S.E. and Posner, M.I. (2012). The attention system of the human brain: 20 years after. Annu Rev Neurosci, 35, 73-89.

Piispala, J., Kallio, M., Bloigu, R. and Jansson-Verkasalo, E. (2016). Delayed N2 response in Go condition in a visual Go/Nogo ERP study in children who stutter. J Fluency Disord, 48, 16-26.

Piispala, J., Määttä, S., Pääkkönen, A., Bloigu, R., Kallio, M. and Jansson-Verkasalo, E. (2016). Atypical brain activation in children who stutter in a visual Go/Nogo task: An ERP study.Clin. Neurophysiol., , 128, 194-203. Popa, D, Popescu, A.T., and Paré, D. (2009). Contrasting activity profile of two distributed cortical networks as a function of attentional demands. J Neurosci, 29, 1191-1201.

Posner, M.I. and Petersen, S.E. (1990). The attention system of the human brain. Annu Rev Neurosci, 13, 2542.

Preibisch, C., Neumann, K., Raab, P., Euler, H.A., von Gudenberg, A.W., Lanfermann, H. and Giraud, A.L.(2003). Evidence for compensation for stuttering by the right frontal operculum. Neuroimage, 20, 13561364.

Raichle, M.E. (2015). The brain's default mode network. Annu Rev Neurosci, 38, 433-447.

Raichle, M.E., MacLeod, A.M., Snyder, A.Z., Powers, W.J., Gusnard, D.A. and Schulman, G.L. (2001). A default mode of brain function. Proc Natl Acad Sci, 98, 676-682.

Romei, V., Rihs, T., Brodbeck, V. and Thut, G. (2008). Resting EEG alpha-power over posterior sites indexes baseline visual cortex excitability. Neuroreport, 19, 203-208.

Rothbart, M.K. (1989). Temperament and development. In G. Kohnstamm, J. Bates, and M.K. Rothbart (Eds.), Temperament in childhood (pp. 187-248). Chichester, England: Wiley. 
Rothbart, M.K., and Posner, M.I. (1985). Temperament and the development of self-regulation. In L.C. Hartlage, and C.F. Telzrow (Eds.), The neuropsychology of individual differences: A developmental perspective (pp 93-123), New York: Plenum.

Salmelin, R., Schnitzler, A., Schmitz, F. and Freund, H-J. (2000). Single word reading in developmental stutterers and fluent speakers. Brain, 123, 1184-1202.

Sengupta, R., Shah, S., Gore, K., Loucks, T. and Nasir, S.M. (2016). Anomaly in neural phase coherence accompanies reduced sensorimotor integration in adults who stutter. Neuropsychologia, 93, 242-250.

Sengupta, R., Shah, S., Loucks, T.M.J., Pelczarski, K., Scott, Y.J. Gore, K., and Nasir, S.M. (2017). Cortical dynamics of dysfluency in adults who stutter. Physiol Rep, 9, doi: 10.14814/phy2.13194

Slagter, H.A., Prinssen, S., Reteig, L.C. and Mazaheri, A. (2016). Facilitation and inhibition in attention: Functional dissociation of pre-stimulus alpha activity, P1 and N1 components. Neurolmage, 125, 25-35.

Sommer, M, Koch, M.A., Paulus, W., Weiller, C., and Büchel, C. (2002). Disconnection of speech-relevant brain areas in persistent developmental stuttering. Lancet, 360, 380-383.

Sowman, P.F., Ryan, M., Johnson, B.W., Savage, G., Crain, S., Harrison, E., Martin, E. and Burianová, H. (2017). Grey matter volume differences in the left caudate nucleus of people who stutter. Brain Lang, 164, 9-15.

Stevens, M.C., Kiehl, K.A., Pearlson, G.D. and Calhoun, V. (2007). Functional neural networks underlying response inhibition in adolescents and adults. Behav Brain Res, 181, 12-22.

Van der Waal, M., Faquhar, J., Fasotti, L. and Desain, P. (2017). Preserved and attenuated electrophysiological correlates of visual spatial attention in elderly subjects. Behav Brain Res, 317, 415-423.

Van Dijk, H., Schoffelen, J-M., Oostenvedl, R. \& Jensen, O. (2008). Prestimulus oscillatory activity in the alpha band predicts visual discrimination ability. J Neurosci, 28, 1816-1823.

Visintin, E., De Panfilis, C., Antonucci, C., Capecci, C., Marchesi, C. and Sambataro, F. (2015). Parsing the intrinsic networks underlying attention: a resting state study. Behav Brain Res, 278, 315-322.

Vogel, A.C., Power, J.D., Petersen, S.E. and Schlaggar, B.L. (2010). Development of the brain's functional network architecture. Neuropsychol Rev, 20(4), doi:10.1007/s11065-010-9145-7

Vollebregt, M.A., Zumer, J.M., Ter Huurne, N., Buitelaar, J.K. and Jensen, O. (2016). Posterior alpha oscillations reflect attentional problems in boys with Attention Deficit Hyperactivity Disorder. Clin Neurophys, 127, 2182-2191. 
Vollebregt, M.A., Zumer, J.M., Ter Huurne, N., Castricum, J., Buitelaar, J.K. and Jensen, O.(2015). Lateralized modulation of posterior alpha oscillations in children. Neurolmage, 123, 245-252.

Watkins, K.E., Smith, S.M., Davis, S. and Howell, P. (2008). Structural and functional abnormalities of the motor system in developmental stuttering. Brain, 131, 50-59.

Wechsler, D. (1991). Wechsler Intelligence Scale for Children, (WISC-III). San Antonio: Psychological Corporation

Xuan, B., Mackie, M-A., Spagna, A., Wu, T., Tian, Y., Hof, P.R. and Fan, J. (2016). The activation of interactive attentional networks. Neurolmage, 129, 308-319.

\section{Captions}

Fig. 1. Group mean wavelets in the Nogo condition from $-700 \mathrm{~ms}$ prestimulus to $2100 \mathrm{~ms}$ poststimulus at frontal (F3, Fz, F4), central (C3, Cz, C4), parietal (P3, Pz, P4) and occipital $(\mathrm{O} 1, \mathrm{Oz}, \mathrm{O} 2)$ channels, children who stutter (CWS) on the top and typically developed children (TDC) on the bottom. The TDC show prominent alpha range activity especially in the posterior areas after the visual stimulus has ended. In CWS, such alpha modulation is hardly visible. Please see the supplementary material for wavelet graphs in Go condition.

Fig. 2. Significantly differing cluster (black) between children who stutter (CWS) and typically developed children (TDC) in Nogo - condition from the full electrode set statistical analysis of wavelet time-frequency space with cluster-level significance $(p<0.025)$ determination. CWS group presents significantly $(p=0.013)$ diminished parieto-occipital and frontal alpha activity in post-stimulus phase. For full electrode layout results please see supplementary materials.

Fig. 3 a. The fast Fourier transformation (FFT) grand average graphs in the time window between 900 and 1800 ms poststimulus in Nogo condition at frontal (Fz), central (Cz), parietal (Pz) and occipital (Oz) channels, children who stutter (CWS) on the left and typically developed children (TDC) on the right. The TDC have a distinct peak in the alpha frequency range between $7,5-12,5 \mathrm{~Hz}$ especially in the occipital area, but in CWS theta range activity between $3,5-7,5 \mathrm{~Hz}$ is more prominent than alpha activity. 
Fig. 3 b. The overlaid individual FFT graphs at Oz channel, CWS on the left and TDC on the right. The individual FFT graphs demonstrate a variable amount of alpha activity in the TDC, but a consistent lack of alpha activity in the CWS.

Fig. 4. The boxplot of the Alpha/Theta ratio at Oz channel, CWS on the left and TDC on the right. The TDC show more variance with two distinct outliers. However, the Alpha/Theta ratio is higher in TDC even without these outliers.

Fig. 5. The $95 \%$ confidence interval of mean graphs for the Alpha/Theta ratio at frontal (F), central (C), parietal (P) and occipital (O) areas for typically developing children (TDC) and children who stutter (CWS) in the Nogo condition. In the TDC variability is higher particularly in the posterior areas. The TDC show a significantly higher occipital Alpha/Theta ratio than the CWS. 


\section{Figure 1 COLOR \\ Click here to download high resolution image}
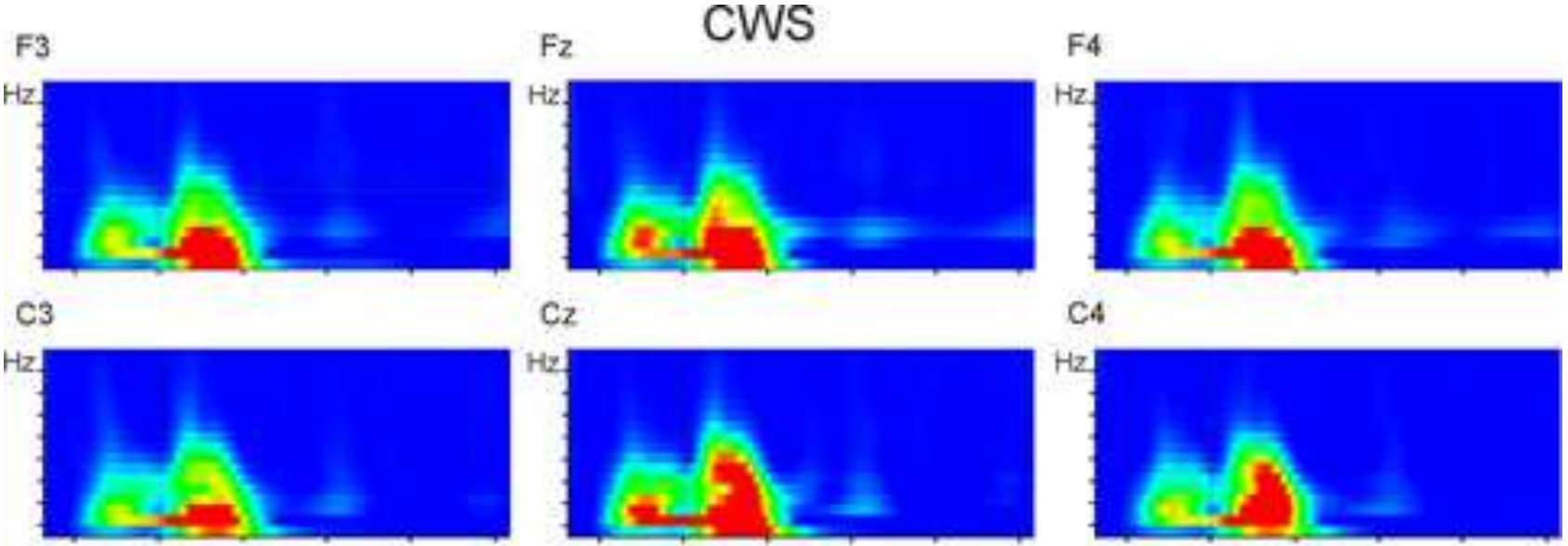

$\mathrm{Cz}$

$\mathrm{C} 4$
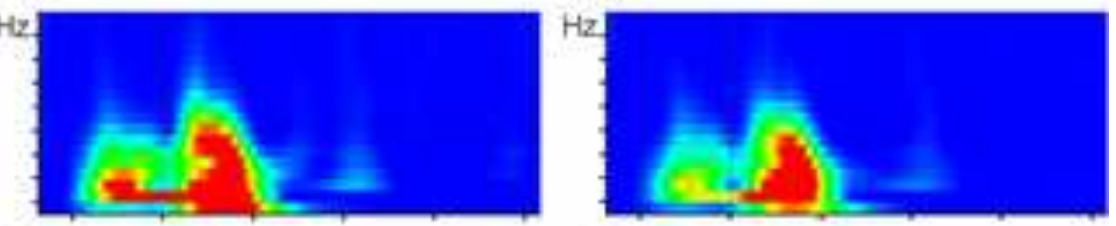

P3

$\mathrm{Pz}$
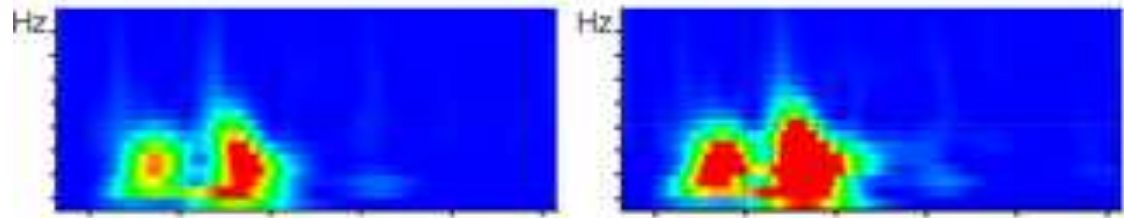

P4

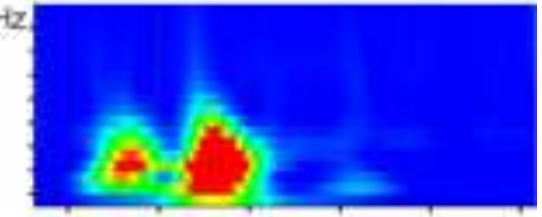

01

$\mathrm{O}_{2}$

$\mathrm{O} 2$
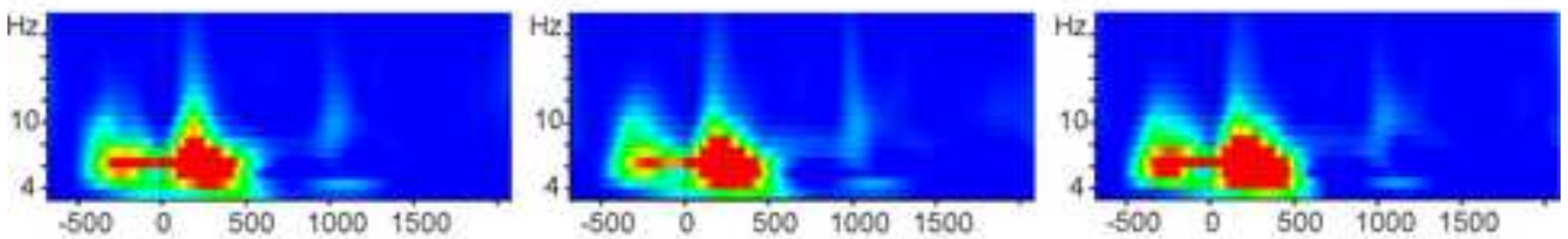

F3

$\mathrm{Fz}$

TDC
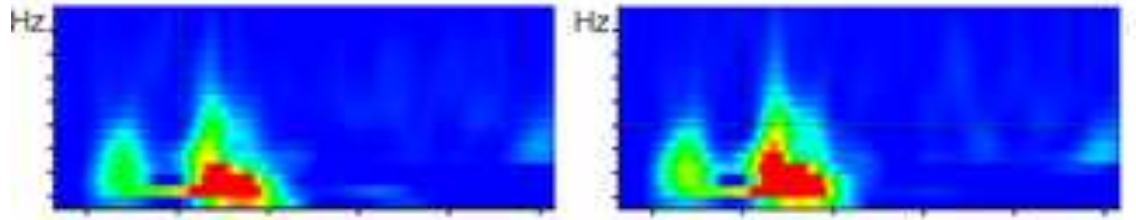

F4

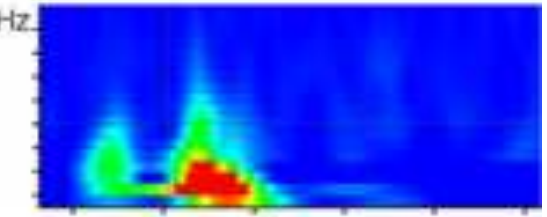

C3

$\mathrm{Cz}$
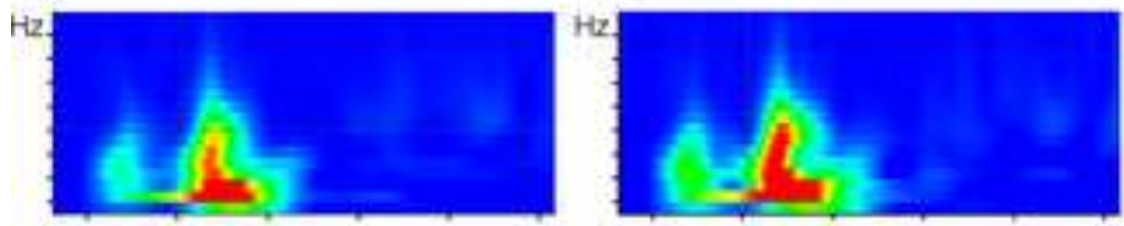

$\mathrm{CA}$

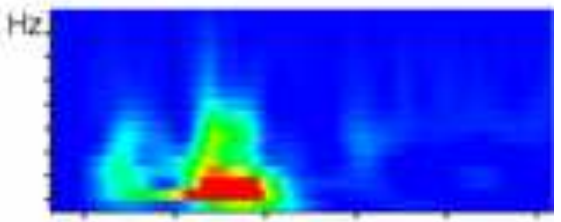

P3

$\mathrm{Pz}$

P4
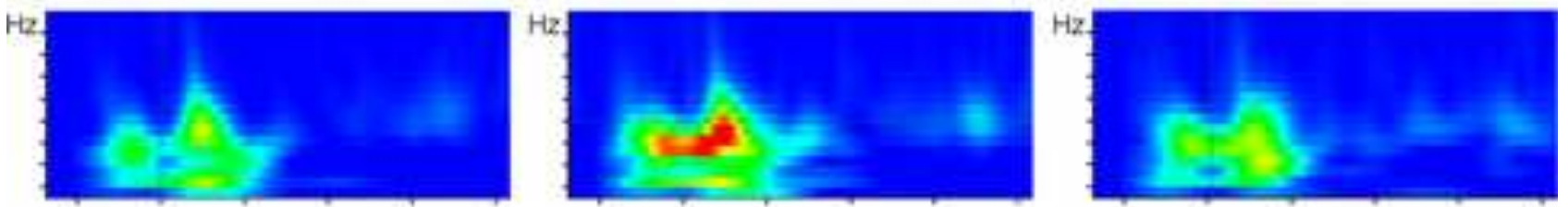

O1

$\mathrm{Oz}$
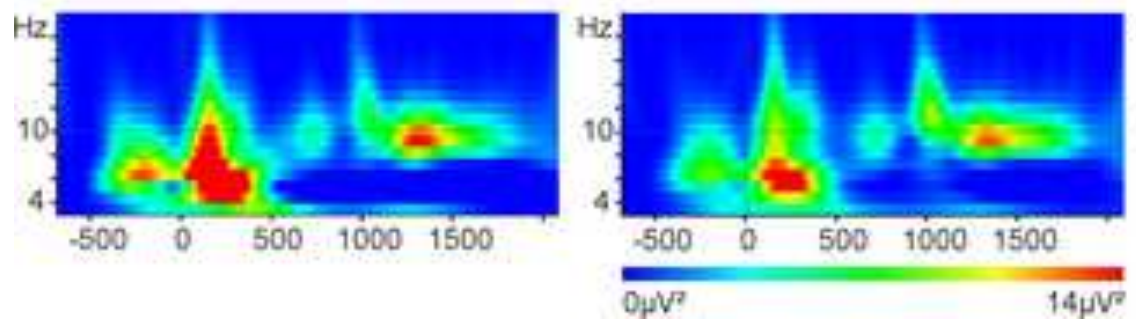

$\mathrm{O} 2$

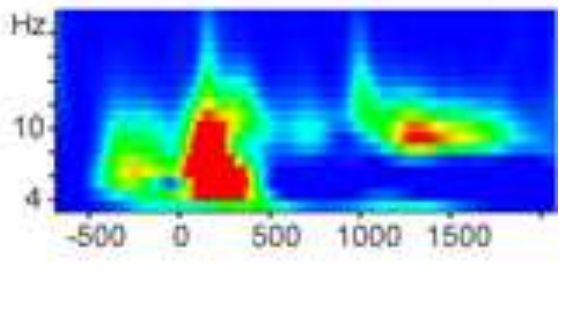


Click here to download high resolution image
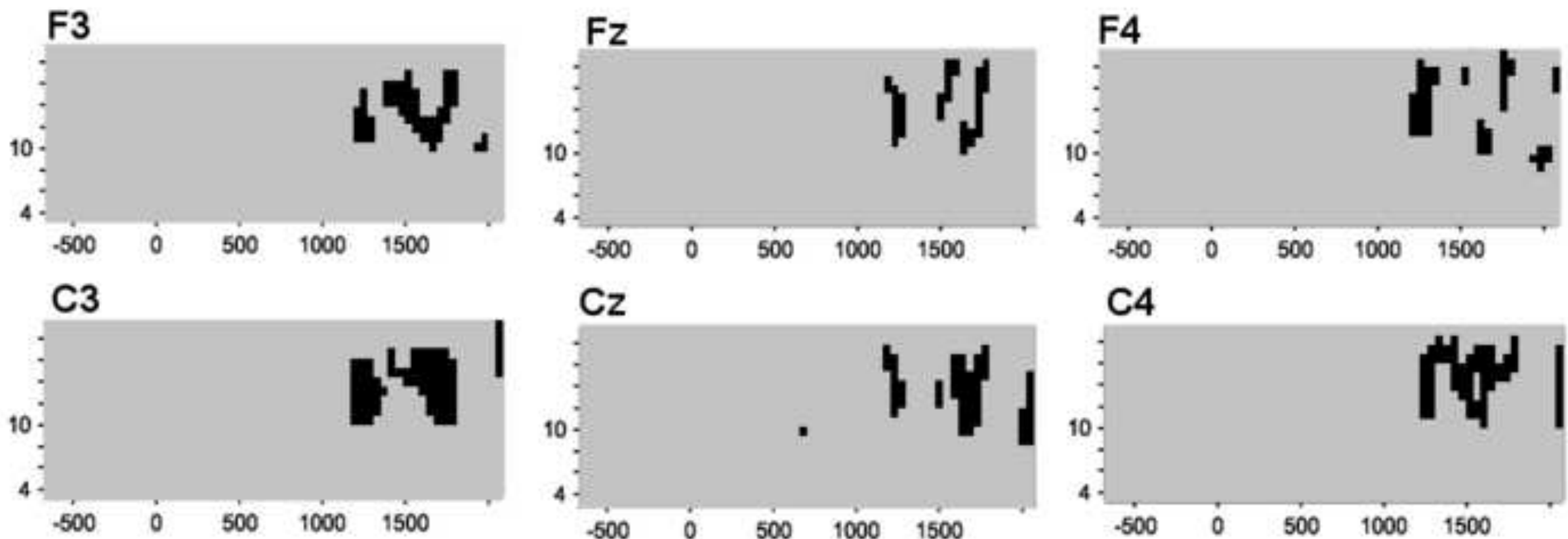

Cz

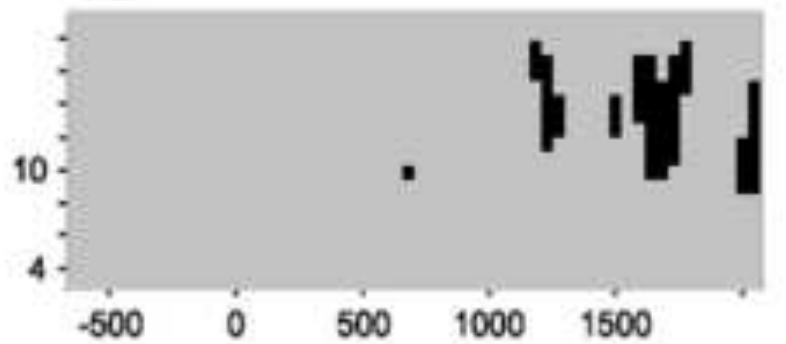

C4
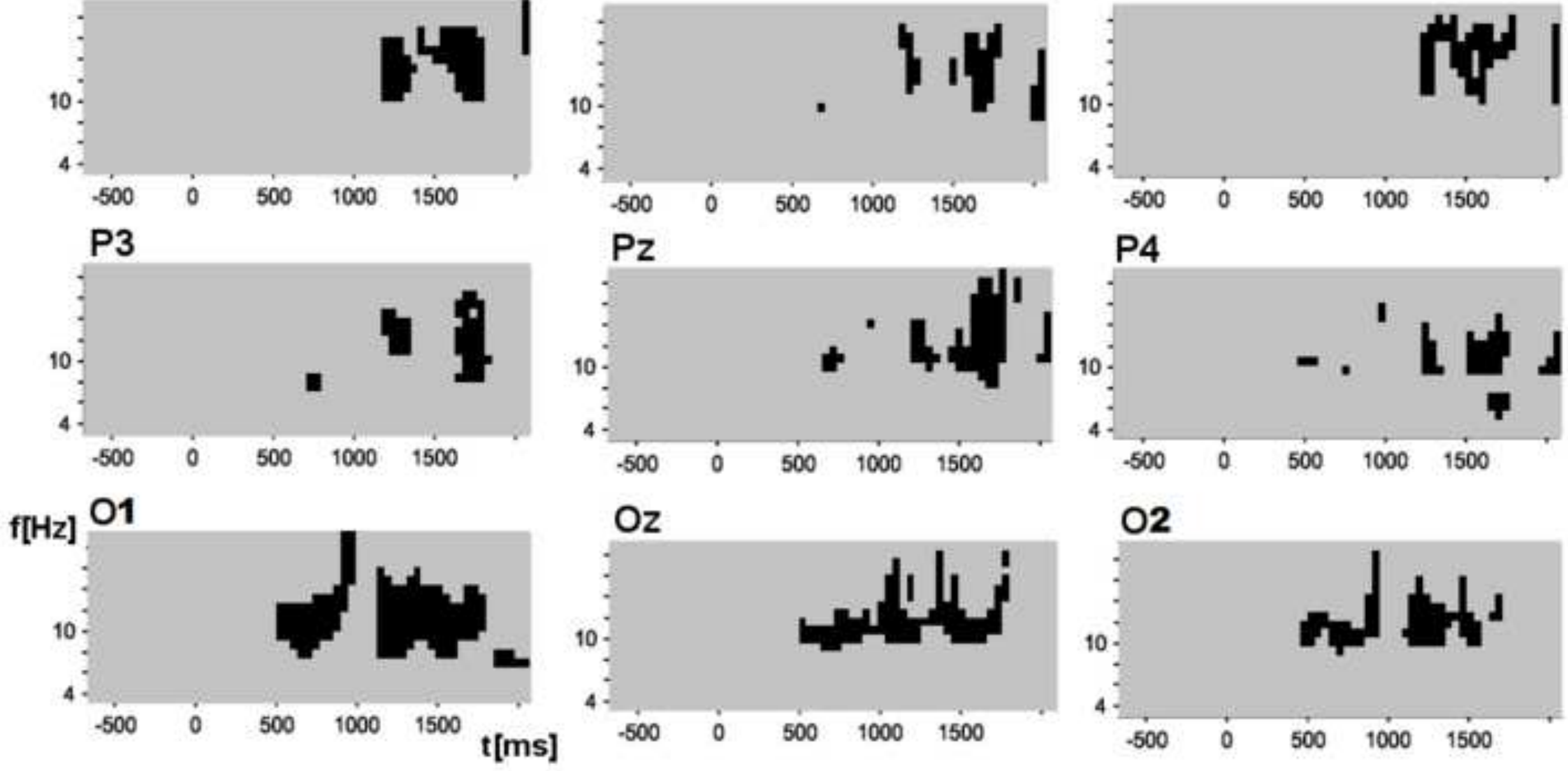
Click here to download high resolution image
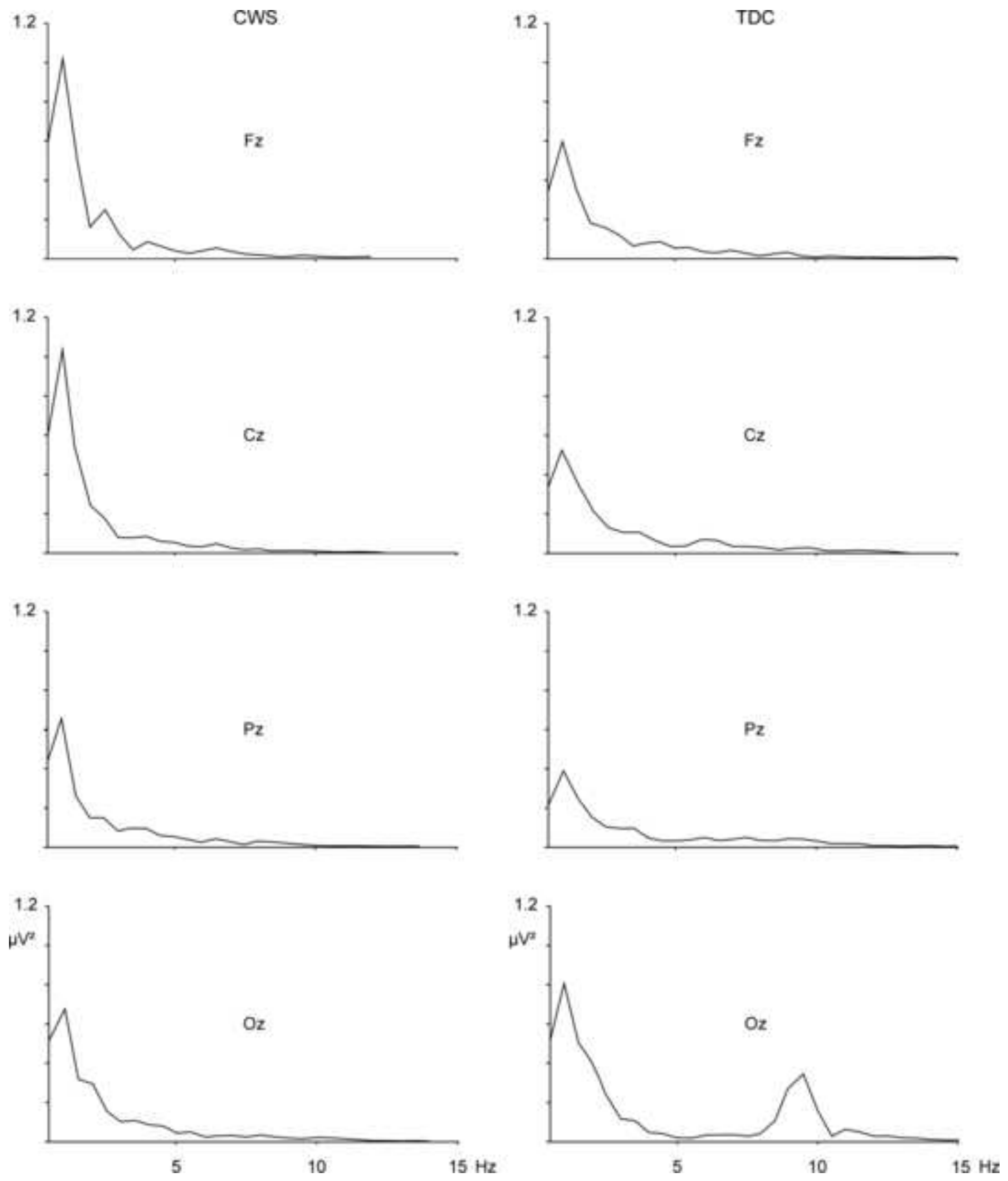
Click here to download high resolution image
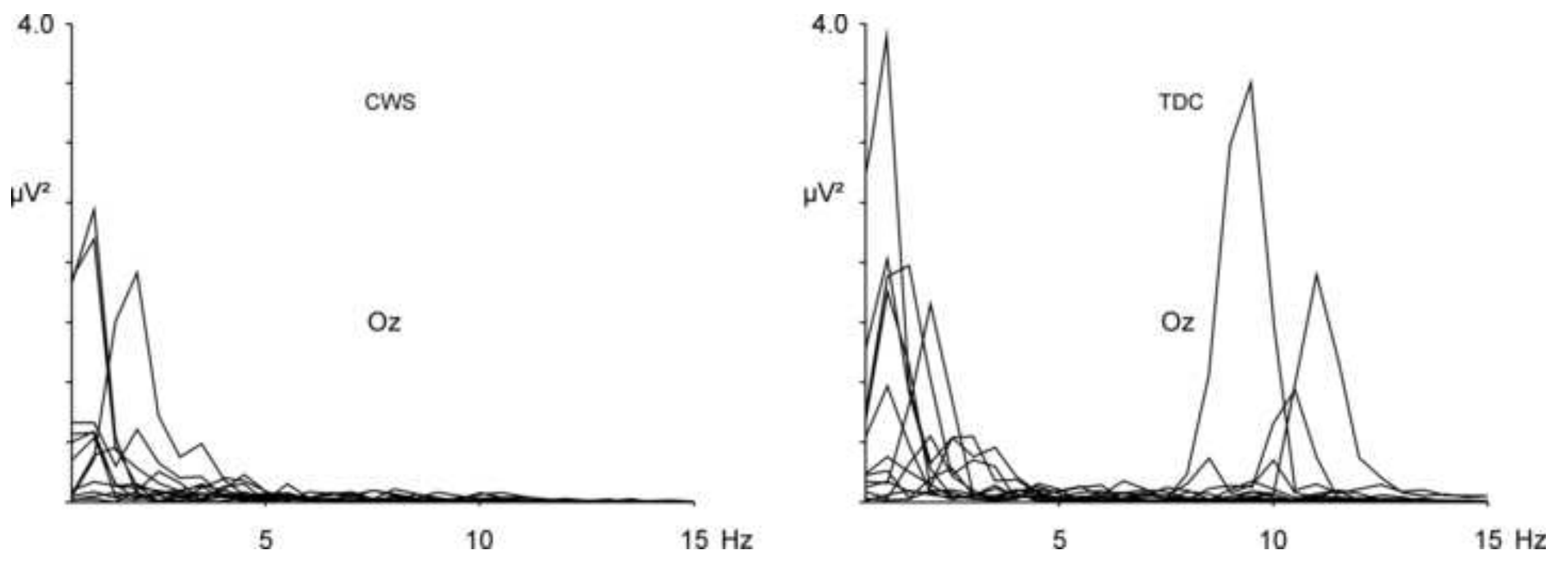
Click here to download high resolution image

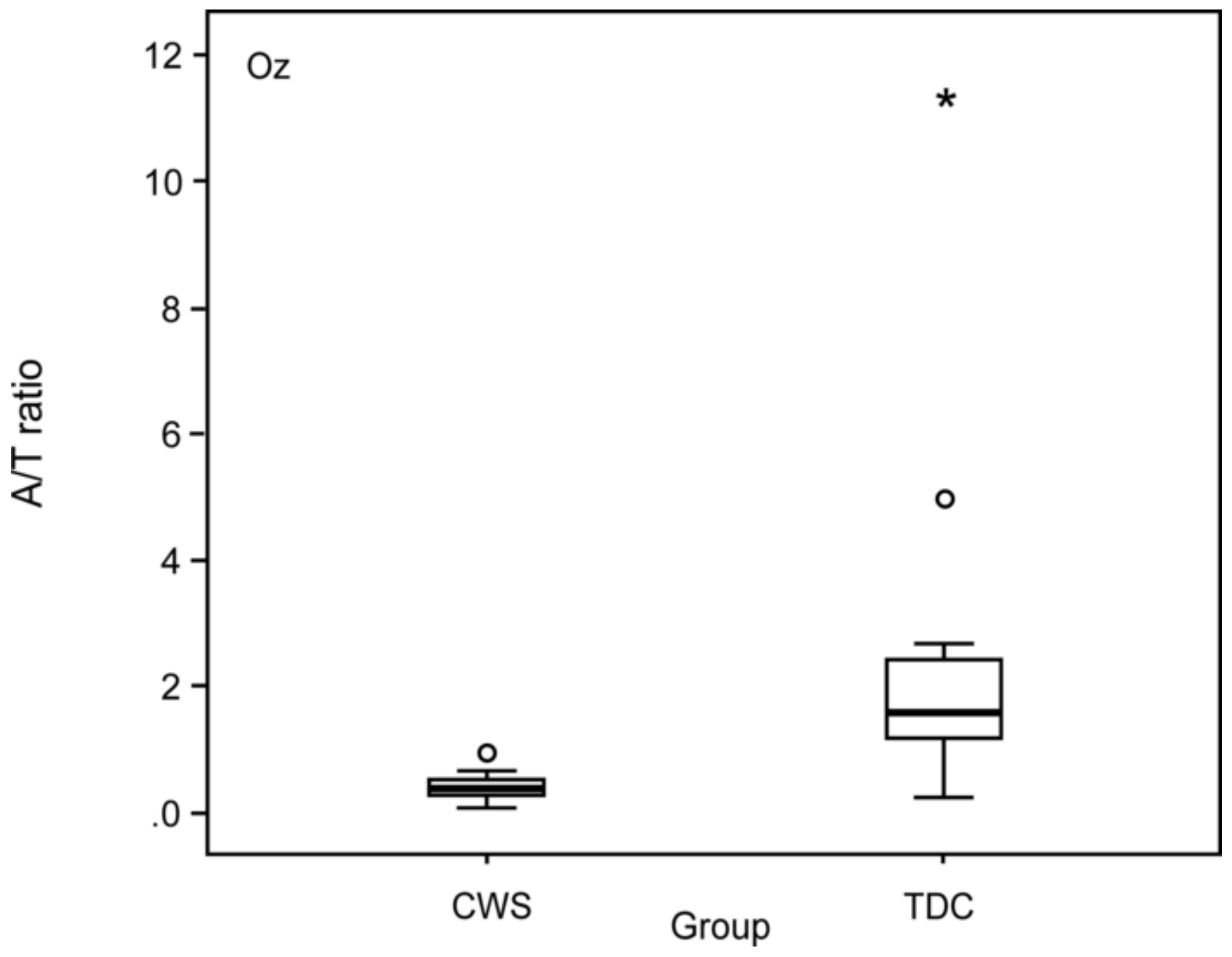




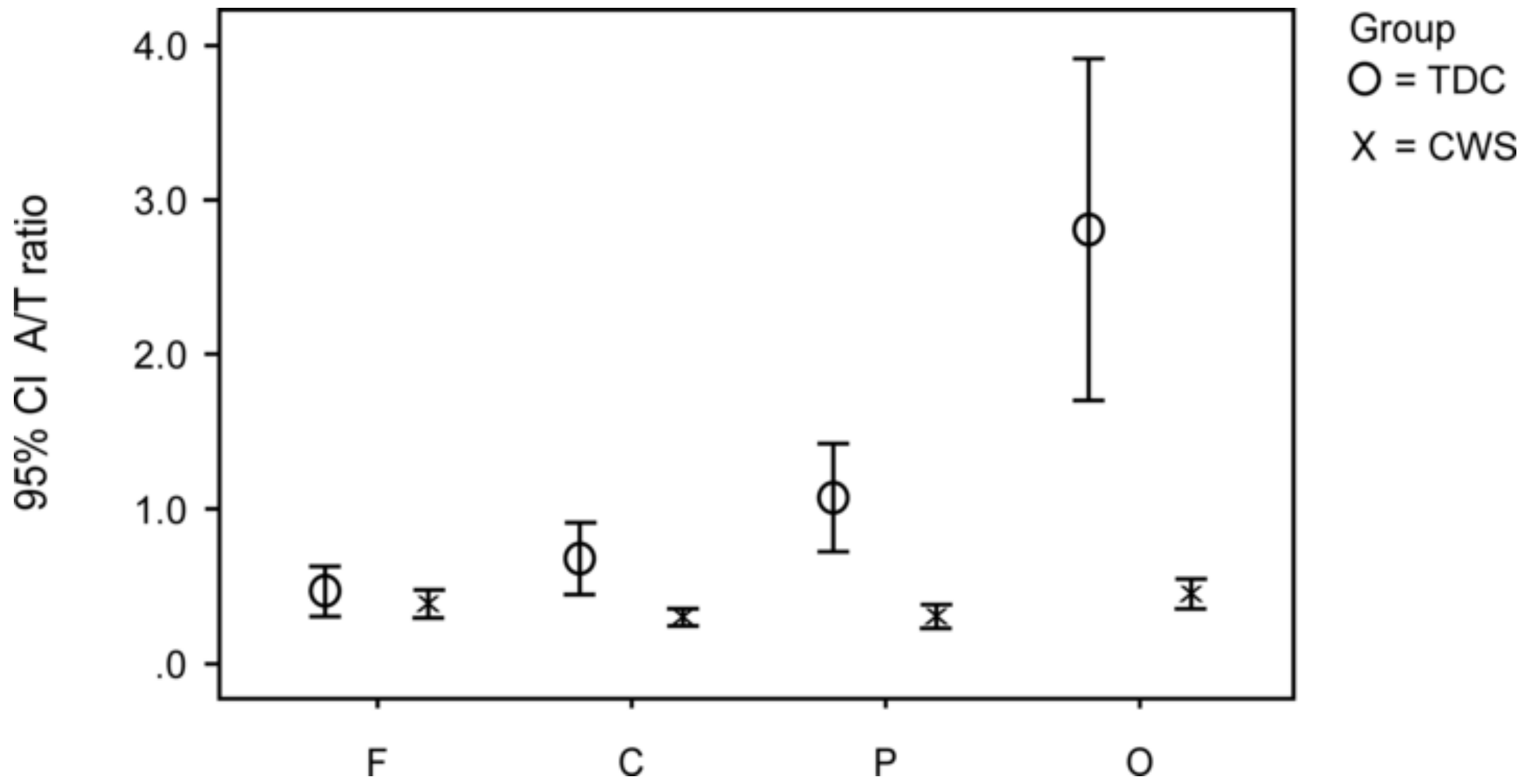




\section{Wavelets in Go condition}

CWS

TDC

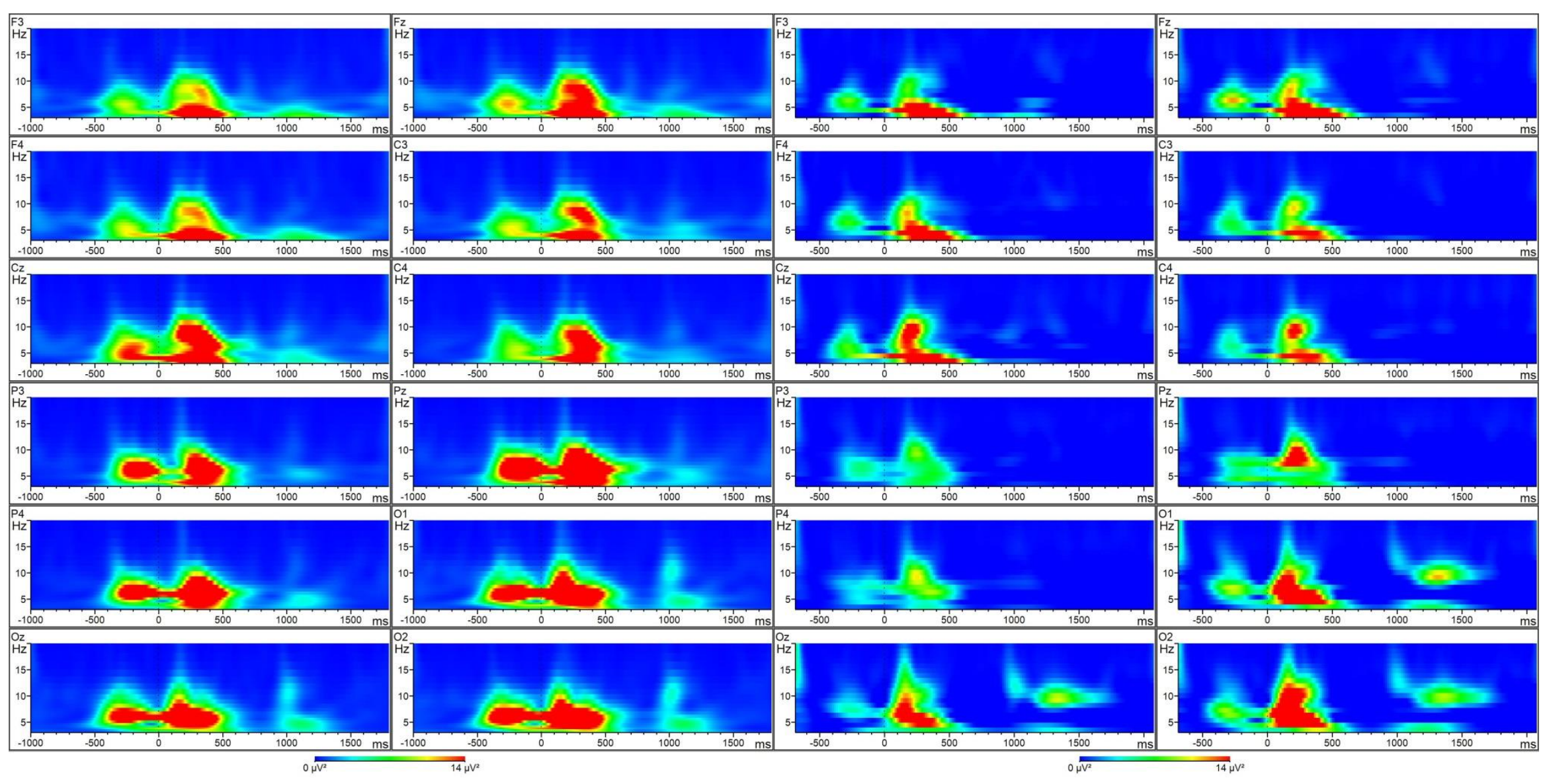




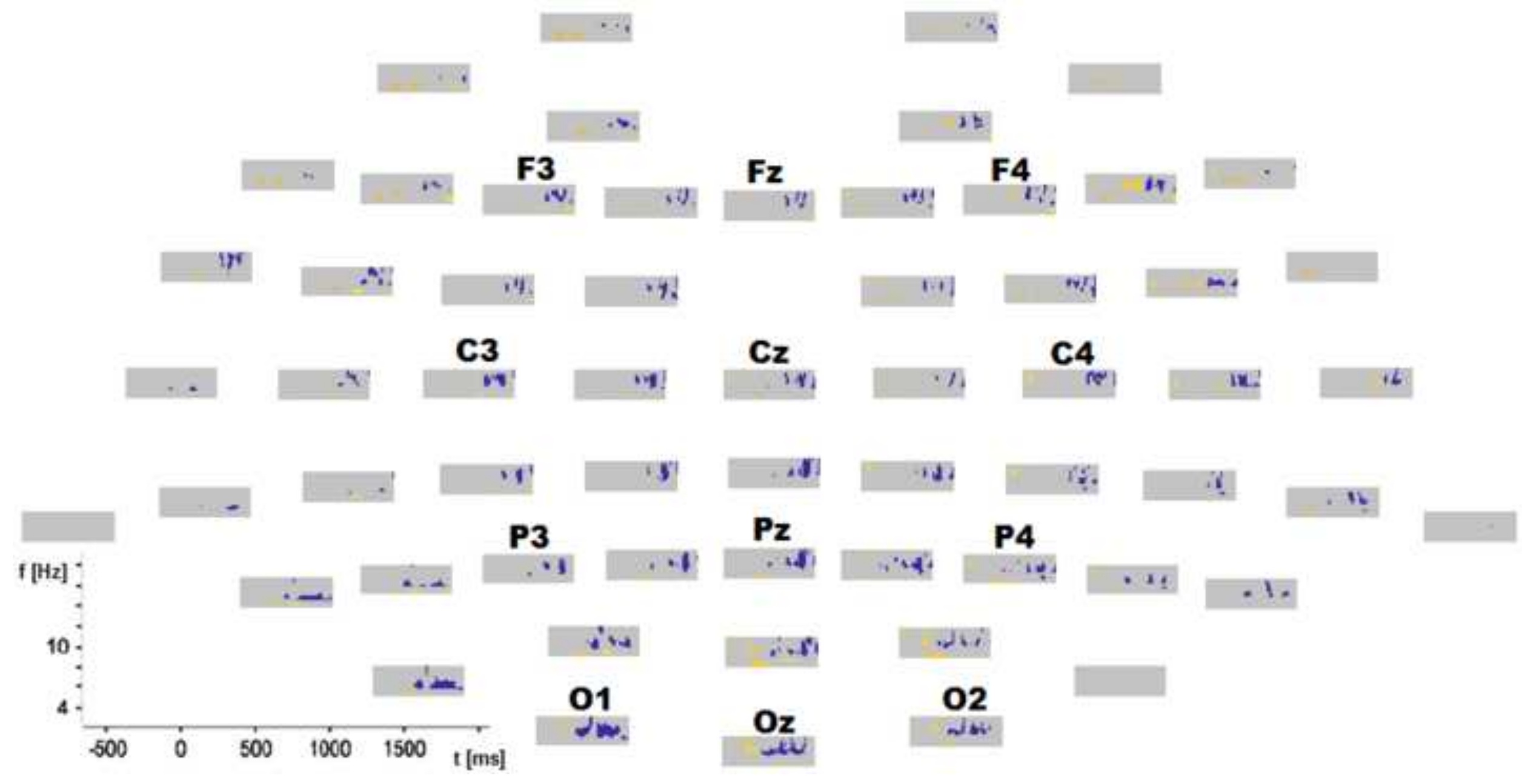




\title{
AUTHOR CONCURRENCE FORM CLINICAL NEUROPHYSIOLOGY
}

\author{
Official Organ of the International Federation of Clinical Neurophysiology (IFCN) \\ http://www.journals.elsevier.com/clinical-neurophysiology
}

\author{
Prof. UIf Ziemann \\ Editor-in-Chief
}

\section{Instructions:}

1. Each submission to Clinical Neurophysiology needs a filled out Author Concurrence Form.

Please fill in the Title of the manuscript below.

2. Collect signatures from all authors.

3a. Scan the form and submit it together with the paper. The submission item is Author Agreement. 3b. If this is not an option, please fax the form to the Editorial Office: $+31-20-485-3881$.

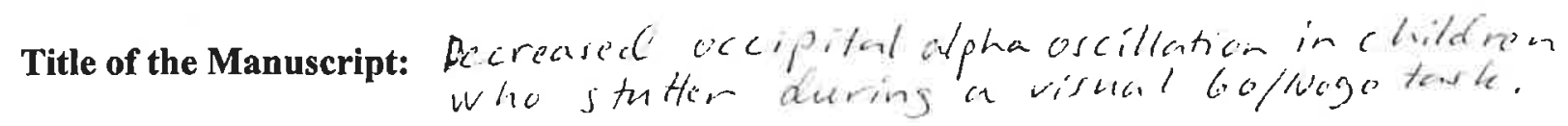
A signature below certifies compliance with the following statements.

Copyright Transfer: In consideration of the acceptance of the above manuscript for publication, the copyright is transferred to IFCN and administered by Elsevier. All proprietary rights other than copyright (such as patent rights) are reserved to the author(s), as well as the right to use original figures and tables in future works, provided full credit is given to the original publication. If the manuscript is work prepared by employee(s) of the United Kingdom or the United States government as part of their official duties, copyright cannot be fully transferred to the IFCN, and authors must check the appropriate box below.

- This manuscript was written in the course of employment by the United Kingdom and it is subject to Crown copyright.

- This manuscript was written in the course of employment by the United States Government and it is not subject to copyright in the United States.

Authorship Responsibility:

The submission is a truthful, original work without fabrication, fraud or plagiarism, and contains no libellous or unlawful statements.

It has not been published previously except in abstract form.

The manuscript is not under consideration for publication, nor will it be submitted for publication, elsewhere until a final decision has been made by this journal.

The undersigned certify that each author has participated sufficiently in the work to take responsibility for its truthfulness and validity, has read the complete manuscript, and concurs with its content.

Conflict of interest disclosure:

All funding sources supporting this work are acknowledged. The authors will disclose to the editor any pertinent financial interests associated with the manufacture of any drug or product described in this manuscript.

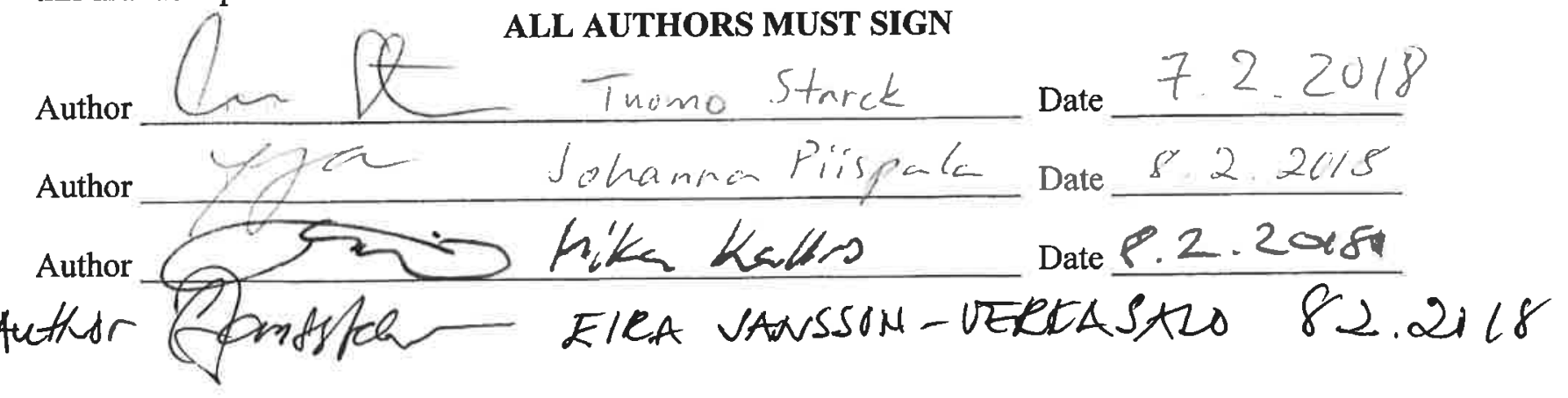

